\title{
A Psychodynamic Approach to Suicide Prevention
}

\author{
Edgar Draper, M.D.* \\ Philip Margolis, M.D.
}

ABSTRACT: This paper sets forth a new theoretical approach to understanding the psychological etiology of suicide. The theory is demonstrated by an in-depth clinical case example, and its implications for the management of the suicidal candidate in his acute interim and long-term care are described. The theory assumes that the primary motivation to suicide comes from a clinically characteristic, unremitting psychological pain. The role of the suicidal prevention center is discussed with specific emphasis on the quality of the engagement between a center staff person and the suicidal patient. A future course for suicide centers is suggested based on the theory.

Although suicide prevention centers have gained a degree of popularity, our experience in such a center at the University of Michigan has brought us up short in two respects: Only $3 \%$ of 1,800 calls or walk-ins presented suicidal problems of any serious degree, but more importantly the quality of the engagement with the suicidal patient appeared crucial. It was this quality that required our scrutiny and evoked our attention to it theoretically and clinically.

In an earlier article (Draper, January '76) one of us set forth a new theoretical approach toward understanding the psychological etiology of suicide, demonstrated a variety of clinical integrations with the theory, and described the implications of the theory for the management of the suicidal candidate in his acute, interim and long-term care.

\section{THE THEORY}

In several respects the theory is a simple one. It assumes that the primary motivation to suicide comes from a clinically characteristic, unremitting psychological pain for which the victim can find no successful anesthesia. It assumes that this pain is precipitated by the physical or psychological loss of a transference figure or transitional object that fills a very specific place in the maintenance of the fact or fantasy that one is loved and valued. It assumes that the encounter with this pain of dreadful aloneness had a specific and significant developmental antecedent. We place this antecedent at the suicidally critical, genetic point of infancy, namely, the protracted period closely following the time that Hartmann called the "undifferentiated stage of development." It is during this period

${ }^{*}$ Dr. Draper is Professor and chairman, Dept. of Psychiatry, University of Mississippi Medical Center, Jackson, Mississippi, 39216. Dr. Margolis is Professor of Psychiatry, University of Michigan Medical Center, Ann Arbor, Michigan 
that the infant becomes increasingly aware of the mother as the mother, the One to whom he relates no longer as a caretaker. It is at this time that the infant becomes highly sensitivie to the One's responses to him, requires her in his environment, and distinguishes her as his first psychologically needed person. The theory's assumption is that if this fully invested mother, now the One, is unable by death, absence, disinterest, depression, neurotic or psychotic alienation to respond to the infant's emotional requests or demands for her loving attention, the suicidogenic seed is sown. The theory assumes that the exquisite sensitivity of the infant to pain of maternal loss (physically or emotionally) must be pinpointed at this developmental stage. The same trauma prior to differentiation would be as relatively unappreciated as loss of a casual baby-sitter (objectless).

After this post-differentiating period is over, although the time of any maternal loss is no doubt traumatic, the repeated loving experiences in the post-undifferentiated period with the real loving One effects establishment of her positive memory on the child's self-value appraisal (object establishment and constancy). Such an untraumatized child is theoretically safeguarded against suicide. To use other language, the suicidogenic trauma (mother's actual or fantasied loss) must be experienced some time close to that period when "recognition memory" has not yet yielded to the higher developmental stage in which the "evocative memory" is established (permanent object) (Piaget, 1962).

In the article entitled "A Developmental Theory of Suicide" (Draper, '76) the theory was "put to work" to help understand such phenomena as the suicidal danger following a serious depressive episode. The author does not consider the danger comes from freed energy that mobilizes the patient then to kill himself. The episode, with equal danger at its inception, is thought to have brought the person regressively deeper than the stage of suicidogenic trauma developmentally. With "recovery" and progression, however, the reencounter, with its painful awareness of the loss of the One, recurs.

Other clinical phenomena that are explained include the variety of clinical diagnoses associated with suicide, for example, schizophrenia, border lines, depressions, and neurotic character disorders. The clinical diagnosis does not in any way necessarily reveal the significant possibilities of the suicidogenic trauma or risk. Rather, the significance of some degree of object cathexis is the critical issue. We thus do not expect a hebephrenic schizophrenic, who is relatively objectless, to commit suicide any more than we would a healthy person who does not give evidence of the developmental trauma indicated. This means, then, that there are many patients and people who become depressed who are very unlikely to commit suicide because there is no evidence of their having sustained the suicidal trauma indicated. The important issue is that the suicidal person's developmental history must have involved sufficient cathexis in the invested One to make the loss of the transference One after infancy devastating. 
With prevention in mind, the loss of such a current transference object, for example, a spouse, makes the suicidal patient nevertheless capable of development of a transference to a new One, such as a therapist, milieu, institution, clinic, or transitional object, permitting a successful "rescue."

Thus although the theory rests squarely on some of Freud's major contributions, this theory of suicide's etiology differs considerably from his. We need the concepts of psychosexual development, regression and fixation, transference, and the economic point of view. We do not need, however, the death instinct, introjection of the hated object, a superego turned sadistic, or aggression against the self (or an introjected object) as the primary motivation, but rather as secondary to the trauma described (Bibring, 1953).

The reexperienced awful pain of the helpless-to-act infant, in his loss of the One, is the primary motivation for suicide in the regressed, but not now helpless-to-act adult whose motoric capabilities permit exit. One can see the primary prevention implications of this theory easily. (If maternal instinctual love does not instruct the mother to recognize the special time of the infanct's need after his undifferentiated period, her education or support might.) Also, for tertiary prevention, the implication of the theory is that the early trauma is not amenable in its developmental primitiveness to "working through". The traumatized patient must be viewed as an indefinite risk with a periodic need for a transference One in the form of a realized substitute, therapist, therapeutic situation, transitional object or belief that supports the fantasy of being cared for by the One.

\section{CASE HISTORY}

A 55-year old patient who read an article on suicide called an author of this paper for an appointment and came to see him. Conspicuous in the history of the 6 years preceding his treatment are a series of losses, including the death of his mother and the disinterest of his wife. Filled with anger and despair, he had left her shortly before his call. According to the patient, his mother was a dominant person in the household. He was deeply attached to her.

The patient was seen about 30 times on a twice-a-week basis. He was in desperate and severe pain during the early sessions, although he attempted to belie his great discomfort by suppressions. He said that it would be a "relief to die"; however, he evinced "a small ray of hope" that the therapist might "deter him from suicide." He recounted several dreams suggesting his ambivalence around suicide-that is, simultaneously displaying a wish for and hope against death. In an attempt to establish his investment in a new One, the therapist voiced his empathy with the patient's pain and was moderately active. The patient moved from a tenuous curiosity in the therapist to a tentative trust. His suicidal thoughts gradually diminished. Since his termination of therapy, he has been in touch occasionally with the therapist by long-distance phone.

Although we do not doubt that patients in suicidal jeopardy do "cry for help" the more important questions are "To whom specifically are they looking for help?" and "What are they asking for?" In our experience, patients in danger are not seeking to be stopped from suicide, per se, but are asking to be relieved of a particular aloneness that carries, characteristically, an awful despairing pain. Furthermore, they are not likely to go to 
new people for help, but usually seek reunion or restitution with the transference One (the lost spouse or friend). If that is not possible, they seek either someone close or similar to the transference One or a long-standing helping friend or professional, from bartender to family physician.

The patient's increasingly painful obsession with suicide, secondary to his inability to find comforting reassurance in his transference One (wife) and with no professionals or friends to whom he could entrust himself led him to cast about for rescue. The literature caught his eye. "Maybe this author knows what I am going through" prompted him to get in touch, not with the suicide prevention center, but with the writer. The patient's initial phone conversation with a prospective rescuer prompted him to come in. The first interview involved a "testing out" of this possible new transference One. Not until he caught some glimmer that the psychiatrist in the first session understood his pain did he agree to return for subsequent visits. The therapist's empathic appreciation of his feelings of aloneness and despair brought him back. The therapist had "passed the test." He learned the therapist's intent was not to remove the patient's last exit from the pain, but to remove the pain. A hope, reflected in several reported dreams, was kindled-hope not for saving his life, but for relief from his obliterating pain.

Thus if the transference One in the suicidal patient's life does not or cannot respond to the cry for help, the patient may kill himself. If the patient risks going to a new source, that new source must offer the kind of response that gives him an inkling of replacement for the One. To have referred the prospective patient on the phone to another therapist or to the suicide prevention center might have proved fatal. Instead, he decided "to give therapy a whirl."

After this tenuous bridge to a new One was made, other bridges to the old ones were not burned or shaken by the therapist in this case. For example, it was clear that some "working through" of the patient's loss of his wife and mother were indicated. The patient was able to return to his wife, who fortunately displayed interest in and affection for him, manifesting (again) some of the transference attributes of the One.

\section{THEORY AND PRACTICE \\ THE SUICIDE PREVENTION CENTER}

Suicide prevention centers have sprung up around the country with the legitimate intent of preventing suicide. It is our intent in this section of the paper to examine the experiences and practices of one center-the Washtenaw County (Michigan) Community Mental Health Center in the light of our clinical experiences and the theory, and to suggest some future courses for suicide prevention centers in general.

Clearly, the concept of having suffered a painful "loss" needs to be dealt with, usually by more than one telephone conversation. The theory takes us back to the mother-child pre-oedipal relationship. We are impressed that during the pre-oedipal period the infant may be seriously affected by real or imagined losses, separation, and threats of abandonment.

In preparing this paper we pulled 12 cases at random out of the 60 showing suicidal symptomatology as presenting complaint. Five were single and living alone and three were divorced and living alone; one was 
alcoholic who had been living with a son who had run away. All complained of an acute "terrible and terrifying aloneness" starkly different from chronic loneliness. Eight of the twelve were self-referrals. It was almost as if there was "nobody around who cares" to make the referral. Unquestionably, temporary or permanent, real or imagined losses "triggered" these contacts. The separations or threats of abandonment involved therapists or caretakers, an abortion, spouses, two runaway children, a boyfriend who died of a "drug reaction," and job loss.

A study of Dorpat and Ripley (1960) supports the conclusion that "unresolved object loss in childhood leads to an inability to sustain object losses in later life." The study cited the prevalence of broken homes in childhood, the death of a parent, and divorce of the parents as significant in a group of 235 completed or attempted suicide. A recent loss of a loved one was a frequent precipitating factor.

The authors are struck by the fact that following a triggering loss, the patient needs "to go right back to the very edge of obliteration ..." (Kubie, 1967). There would appear to be a wish on the patient's part to return to adolescence (and then infancy?) and to live life over again.

To counteract the current trauma and the subsequent pain in the regression, more than one contact may be necessary in order to learn the precipitant loss (often obvious) and to develop the center or its therapist as a new but significant transitional transference object. A contact is maintained until a bridge is established to the new One, especially if the old One (real-life transference object) is unavailable. If hope is not completely dead (if it is, no telephone call will be made), the suicide prevention center can represent the transference One to the person who has regressed to the developmental "danger zone." The theory holds that the expectations of the patient regarding the transference figure must be acknowledged. Either this figure must be supplied or the loss reconciled to move the patient progressively out of the suicidal danger zone.

The "more than one contact" and the "continuing availability"concepts are crucial. One author states that if "somebody will make an attempt or feel if only for a fleeting second that he cares whether the patient lives or dies" (Stengel, 1965), it may be enough to tide him over a difficult time. In our opinion, "a fleeting second" is not usually enough to enliven the "Oh, you're back!" type of "recognition memories." In the experience of our center (a) continuing contacts are useful; (b) suicide prevention includes crisis aversion by intervention of a new One; (c) the involvement of the "significant other" dilutes alienation from the One; (d) searching out alternative substitutes for the patient's lost One may be life saving; and (e) primary preventive measures for mothers of infants must be considered.

All 12 cases here involve more than one contact (two to eight) between the center and the caller or walk-in. Initiative for making contacts beyond the first one was evenly divided between the center and its clients. It is conceivable, of course, that the center staff was "overanxious" in some 
instances and need not have called back. As it happened, all 12 had "successful" outcomes (that is, they did not commit suicide and they either got into a treatment situation or spontaneously remitted).

Several studies appear to confirm the multiple contact idea. Ringel (1966) had only one suicide out of 2,879 patients in 8 to 44 months after the initial attempt; he attributed this almost zero rate to the treatment and attention offered after the attempt (Ringel, 1966).

Clearly, then, the suicide prevention center must be ready to provide (a) emergency care (one to three contacts), (b) interim or transitional care (one to ten contacts), and (c) access to long-term care-either via carefully executed referral or by being a stable receptive clinic as a future alternative to suicide. The center may perform crisis intervention, brief psychotherapy, or offer long-standing "institutional transference" stability. Its staff may work through a grief reaction with the patient; in some instances it may act to help bring back the "lost" object. Efforts are often aimed at "reinforcing the ego defenses, renewing the feeling of hope, love, and trust, and providing emergency scaffolding..." (Litman, 1967).

One of the main features of suicidal crisis therapy is the gradual involvement of others. As Farberow suggests, "The responsibility for the patient rests with the worker until the situation is handled by some other resource. To this extent the patient is transferred rather than referred" (Farberow, 1967). From our perspective, a successful "transfer" carries the potency of involvement from the old One to the new transference One.

In our 12 random cases, 5 were returned to significant "helping" people with whom they had had a previous relationship-counselor, psychiatrist, family physician, social worker, and minister. The center staff person was the "contact man" with the patient's family in several instances and enabled two patients to hospitalize themselves voluntarily. It is of interest that the longer the phone conversation, the more likely that an appropriate referral for an ongoing relationship could be made. A mobilization of "significant others" enables a salutary return to transference One(s) to be made. The center is thus accessible as a source of help, especially when all other sources have failed.

In a certain sense the therapist acted as a "suicide prevention center" for our case. The therapist was available and accessible; he provided the patient with a "virtually unlimited albeit temporary source of dependency gratification" (Farberow, 1967). The patient moved out of the danger zone. The questions are when, how, and should disengagement occur? Does the center (therapist) terminate, transfer, or do long-term psychotherapy? The answers obviously have to be based on the individual case situation. (With the above case there was a mutual recognition that the patient was out of danger, that his pain had subsided, and that further treatment was not indicated. Phone calls varying from one per month to three per month have characterized the past couple of years.) Both engagement and disengagement, however, are critical issues to be addressed by the suicide pre- 
vention center. A study at Dartmouth College indicates that a typical suicide prevention clinic does not very often deal with the patients who are most likely to commit suicide in the immediate future (Maris, 1968). We would agree. So, what about those suicidal people who do not call? We suspect that the answer lies in a suicide prevention program sponsored by, planned by, and activated by centers. In order to head off a suicidal crisis and work for the maintenance of mental health, centers need to undertake a primary preventative program for the future generation's well being-in essence, to provide appropriate education and treatment programs to deal prophylactically for those genetically critical 6 to 18 months of infancy. (This kind of primary prevention is precisely the work of Ann Arbor's Infant Development Project under the direction of Professor Selma Fraiberg.)

Centers often need to follow up, in a persistent fashion, suicide attempters. We need to consider fielding an aggressive case-finding operation via community "outreach" and other methods. We must begin to identify high-risk individuals and evolve techniques for making contact and initiating action "prior to the efflorescence of the suicide crisis" (Farberow, 1967). Centers might serve a consultative function for a variety of community caretakers. For example, in two different instances of the 12 random cases, the center here consulted with two physicians in the emergency room of the community hospital around the care of their suicidal cases.

Finally, the educational value of talking with nonpsychiatric physicians, ministers, and others should not be underestimated. It may just be that as simple an action as helping a mother refrain from an extended trip away from her baby at those indicated genetically critical points in time can exemplify a truly primary suicide prevention for that particular little one.

\section{REFERENCES}

Bibring, E. The mechanisms of depression In P. Greenacre (Ed.), Affective disorders. New York: International Universities Press, 1953.

Dorpat, T.L., \& Ripley, H.S. A study of suicide in the Seattle area. Comprehensive Psychiatry, 1960, 1, 349-359.

Draper, E. A developmental theory of suicide. Comprehensive Psychiatry, 17 pp. 63-80 January February, 1976.

Farberow, L. Crisis, disaster, and suicide: Theory and therapy. In E. S. Schneidman (Ed.), Essays in self-destruction. New York: Science House, 1967.

Kubie, S. Multiple determinants of suicide. In E. S. Schneidman (Ed.), Essays in selfdestruction. New York, Science House, 1967.

Litman, E. Sigmund Freud on suicide. In E.S. Schneidman (Ed.), Essays in self-destruction. New York: Science House, 1967.

Maris, R. Unpublished paper, May, 1968.

Piaget, J. Play, dreams, and imitation in childhood. New York: Norton, 1962.

Ringel, E. The prevention of suicide, a world-wide problem. Mental Hygiene, 1966, 55, 84-105.

Stengel, E. Suicide and attempted suicide. Bristol. Conn.: MacGibbon \& Kee, 1965. 